\title{
Effect of sol-gel processing parameters on structure of zirconia
}

\author{
D. G. da Silva ${ }^{1 *}$, W. L. Vasconcelos ${ }^{1}$ \\ ${ }^{I}$ Federal University of Minas Gerais, Department of Metallurgical and Materials Engineering, \\ Laboratory of Ceramic Materials, Belo Horizonte, MG, Brazil
}

\begin{abstract}
The present study reports the experimental results regarding the effect of molar ratio of hydrolysis water used in the sol-gel synthesis upon the structure of zirconia. The $\mathrm{ZrO}_{2}$ materials were synthesized via simple metal-chelate route using zirconium n-propoxide $\left[\mathrm{Zr}\left(\mathrm{OCH}_{2} \mathrm{CH}_{2} \mathrm{CH}_{3}\right)_{4}\right]$, n-propanol, acetic acid, and deionized water. Thermogravimetric analysis and infrared spectroscopy were performed to evaluate the structural evolution upon samples heating; the complete removal of organic compounds at $330{ }^{\circ} \mathrm{C}$ was verified. The results of $\mathrm{X}$-ray diffraction showed that the calcination temperature of $400{ }^{\circ} \mathrm{C}$ was enough to the crystallization of the metastable tetragonal zirconia phase. Nitrogen adsorption-desorption measurements indicated that the textural properties of zirconia were affected by the water content used in the synthesis, and the highest surface area was achieved when the water molar ratio of 4 was used.
\end{abstract} Keywords: zirconia, sol-gel, metal-chelate route, hydrolysis water.

\section{INTRODUCTION}

Metal oxides represent one of the most important and widely employed categories of solid catalysts, either as active phases or supports. They are utilized both for their acid-base and redox properties and constitute the largest family of heterogeneous catalysts [1-3]. Among them, $\mathrm{ZrO}_{2}$ has attracted a great deal of attention due to its both acid and base active centers on the surface as well as oxidizing and reducing sites [4]. Moreover, abundant oxygen-containing functional groups, as well as unsaturated Lewis acid-base $\mathrm{Zr}^{4+}-\mathrm{O}^{2-}$ pairs, make $\mathrm{ZrO}_{2}$ a widely novel material for ion exchange membranes, oxygen [5] and $\mathrm{NO}_{\mathrm{x}}$ sensors [6], adsorption and separation [7-14], catalyst and catalyst support [15-17], controlled release of pharmaceutical ingredients [18], solar light absorption layer in solar cells [19], and so on. To obtain zirconia nanoceramics, various methods and techniques have been developed and investigated, including sol-gel process, hydrothermal process, and precipitation method. Among these methods, however, the sol-gel process is found to be a simple and versatile technology for the synthesis of zirconia-base materials on large scale [2, 3, 20, 21].

Sol-gel has the great advantage to use low temperatures to prepare a wide range of materials forms, from fibers through dense ceramics and aerogels [22,23]. Sol-gel chemistry is based on inorganic polymerization reactions. In general, the precursors are dissolved in a suitable solvent and hydrolysis and condensation reactions are catalyzed, typically by the presence of an acid or base in the starting solution. Different inorganic and hybrid organic gels can be formed using this approach [24, 25]. However, one of the greatest problems in sol-gel synthesis of zirconia-based materials is that the

*debora-g-s@hotmail.com

(D) https://orcid.org/0000-0002-7555-0950 precursor hydrolysis is faster than the condensation, resulting in precipitation of $\mathrm{ZrO}_{2}$ particles. To increase the hydrolytic stability, chelating agents are added to the synthesis in an amorphous metal-chelate route. For example, acetylacetone and acetic acid were used as chelating agents to diminish the hydrolysis rate [20, 26, 27].

In the sol-gel synthesis, the amount of water determines the degree of hydrolysis and the type of initial species formed, thus influencing the secondary polycondensation reactions which involve the polymerization of hydrolyzed metal alkoxides in alcoholic solution. This, in turn, affects the chemical and structural makeup of the resultant polymer molecules. If the water molar ratio (r) in the synthesis is equal or greater than 4 , the metal alkoxide could hydrolyze completely (Eq. A); otherwise, $(r<4)$ only partial hydrolysis takes place (Eq. B) [28, 29]:

$$
\begin{aligned}
& \mathrm{M}(\mathrm{OR})_{4}+4 \mathrm{H}_{2} \mathrm{O} \rightarrow \mathrm{M}(\mathrm{OH})_{4}+4(\mathrm{ROH}) \\
& \mathrm{M}(\mathrm{OR})_{4}=\mathrm{r} \mathrm{H}_{2} \mathrm{O} \rightarrow \mathrm{M}(\mathrm{OR})_{\mathrm{r}}(\mathrm{OH})_{4-\mathrm{r}}+\mathrm{rROH}
\end{aligned}
$$

This study aimed to investigate the relation upon the effect of molar ratio of hydrolysis water used in a sol-gel synthesis on the final structure of zirconia. Its effect on the rheology of the sols and sample thermal behavior were also discussed.

\section{EXPERIMENTAL}

Synthesis of zirconium oxide: Fig. 1 shows the procedure used in the syntheses of zirconium oxide using the metalchelate method. Zirconium n-propoxide (ZrP, 70\% solution in propanol, Sigma Aldrich) was used as a precursor, n-propanol (99.7\% pure, Sigma Aldrich) as a solvent, glacial acetic acid (99.85\% pure, Sigma Aldrich) as a catalyst and stabilizer, and deionized water $\left(\mathrm{H}_{2} \mathrm{O}\right)$ for the hydrolysis. The 
hydrolysis water content was investigated using the molar ratios (r) of $\mathrm{ZrP}: \mathrm{H}_{2} \mathrm{O}$ of 1:2, 1:4 and 1:6. The reagents were mixed and homogenized for $1 \mathrm{~h}$ in a magnetic stirrer. The precursor solution was placed in acrylic containers and aged for 7 days at $60{ }^{\circ} \mathrm{C}$ under static condition. Then the alcogels were kept at $100{ }^{\circ} \mathrm{C}$ for 3 days for drying. Subsequently, they were heat treated in air for $10 \mathrm{~h}$ at $400{ }^{\circ} \mathrm{C}$.

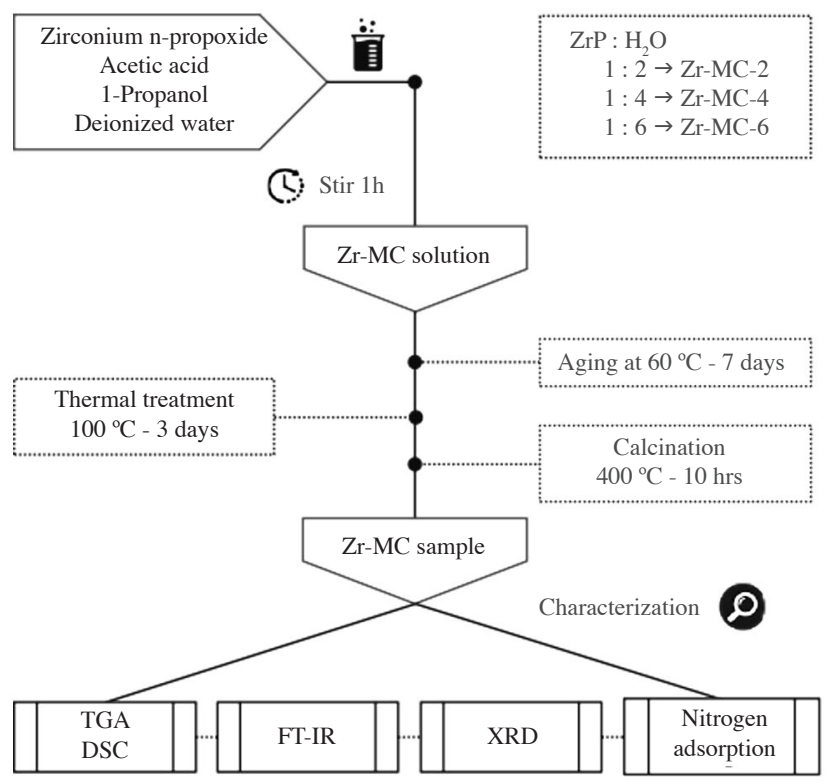

Figure 1: Procedure of zirconium oxide synthesis and characterization.

Characterization: the zirconium oxide samples were characterized by thermogravimetric analysis, TG-DTG, and differential scanning calorimetry, DSC (PerkinElmer, STA 6000), using synthetic air in the range of $80-480{ }^{\circ} \mathrm{C}$. Nitrogen adsorption-desorption (Quantachrome, Autosorb 1-C) was used to evaluate the specific surface area (BET method) and pore structure (NLDFT and Monte-Carlo method) of the samples. The X-ray diffraction patterns of the samples with different heat treatment temperatures were obtained using Philips equipment, PANalytical PW 1710, in the range of $20-70^{\circ}(2 \theta)$. For the identification of the crystalline phases, X-ray diffraction (XRD) results of the samples were compared with the XRD patterns of references obtained from the JCPDS database, file number PDF \#88-1007 for tetragonal structure. To follow the material transformations induced by heating, Fourier-transform infrared spectroscopy, FT-IR, analysis (PerkinElmer, FT-IR/ FIR Spectrometer Frontier) of all samples was carried out as a function of temperature.

\section{RESULTS AND DISCUSSION}

A homogeneous, transparent and fluid solution was obtained with the three syntheses described previously. The hydrolysis water content greatly affected the rheology of the sols; the gelation time decreased drastically with the increase in water molar ratio (r), as shown in Table I. The solution
$\mathrm{pH}$ was measured and a value of $3.8 \pm 0.2$ was found. The zirconium polymerization depends on the synthesis $\mathrm{pH}$ value and the presence of complexing species, being possible to obtain products with different compositions and structures. Polymerization is more rapid with a higher $\mathrm{pH}$ value since more $\mathrm{OH}^{-}$groups are available to promote linking of edges of the tetrameric units, whereas a lower $\mathrm{pH}$ gives rise to slower polymerization and more ordered structure, favoring the synthesis of nanocrystalline structures [30]. Thus, it is important to control the synthesis $\mathrm{pH}$, once differences in preparation $\mathrm{pH}$ can lead to structural changes in zirconium hydroxide obtained and, in turn, affect the crystallization temperature, growth rate and phase transformation of zirconia.

Table I - Dependence of gelation time on hydrolysis water content.

\begin{tabular}{cccc}
\hline Sample & Zr-MC-2 & Zr-MC-4 & Zr-MC-6 \\
\hline Hydrolysis water content (r) & 2 & 4 & 6 \\
Gelation time (h) & 120 & 24 & 5 \\
\hline
\end{tabular}

Thermal behavior: Fig. 2 shows the results of thermal analysis of the sample thermally treated at $100{ }^{\circ} \mathrm{C}$ for $72 \mathrm{~h}$. The samples presented approximately the same thermal behavior as shown in the thermogravimetric (TG) and derivative thermogravimetry (DTG) curves, with a total mass loss of $30 \%$ at $480{ }^{\circ} \mathrm{C}$. Moreover, the differential scanning calorimetry (DSC) curves showed about the same temperature range for the endothermic and exothermic peaks. In the TG-DTG curves, the first mass loss $\left(\sim 125^{\circ} \mathrm{C}\right)$ corresponded to an endothermic peak in the DSC curve and was related to the desorption and evaporation of water and 1-propanol from the porous gel network. The presence of free water in the structure even after being heat treated at $100{ }^{\circ} \mathrm{C}$ for $72 \mathrm{~h}$ was also verified in the FT-IR spectra (Fig. 3), which exhibited a broad band between 3600 and $3200 \mathrm{~cm}^{-1}$ that was assigned to the $v(\mathrm{O}-\mathrm{H})$ stretching vibration modes of chemisorbed water $[2,31,32]$. The intensity of the $\mathrm{O}-\mathrm{H}$ band was no more visible for samples calcined at $200{ }^{\circ} \mathrm{C}$, indicating the complete elimination of chemisorbed water. The second mass loss in the TG-DTG curves $\left(\sim 215^{\circ} \mathrm{C}\right)$ was associated with an endothermic event in the DSC curve and was due to the thermal decomposition of remaining organic compounds such as the propoxy group of unreacted zirconium propoxide. The FT-IR measurements confirmed the removal of organic compounds for the heat treatment temperature of $300{ }^{\circ} \mathrm{C}$ based on the disappearance of characteristic peaks of stretching $v(\mathrm{C}-\mathrm{H})\left(3000-2800 \mathrm{~cm}^{-1}\right)$ and bending $\delta(\mathrm{C}-\mathrm{H})$ (1400-1350 $\mathrm{cm}^{-1}$ ) modes of the groups $-\mathrm{CH}_{3}$ and $-\mathrm{CH}_{2}$ and the peaks of skeletal stretching of $v(\mathrm{C}-\mathrm{O}) \mathrm{Zr}\left(\sim 1100 \mathrm{~cm}^{-1}\right)$ in the propoxy group of zirconium propoxide [2, 31, 32]. However, according to Fig. 3, the temperature of $300{ }^{\circ} \mathrm{C}$ was not sufficient to remove the acetate coordination groups $v\left(\mathrm{COO}^{-1}\right)\left(1546\right.$ and $\left.1447 \mathrm{~cm}^{-1}\right)$. These peaks vanished from the FT-IR spectra only with the calcination temperature of $400{ }^{\circ} \mathrm{C}$. Therefore, it can be concluded that the strong broad 

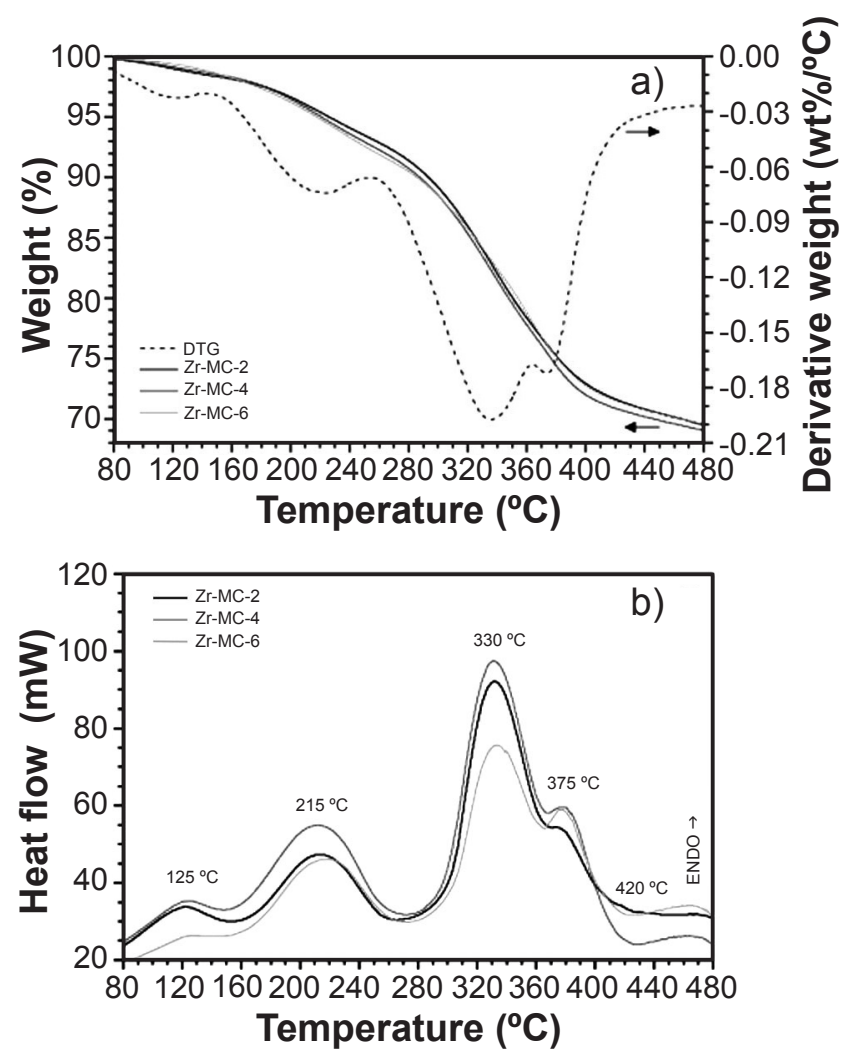

Figure 2: TG-DTG (a) and DSC (b) curves of dry gels with different amounts of hydrolysis water.

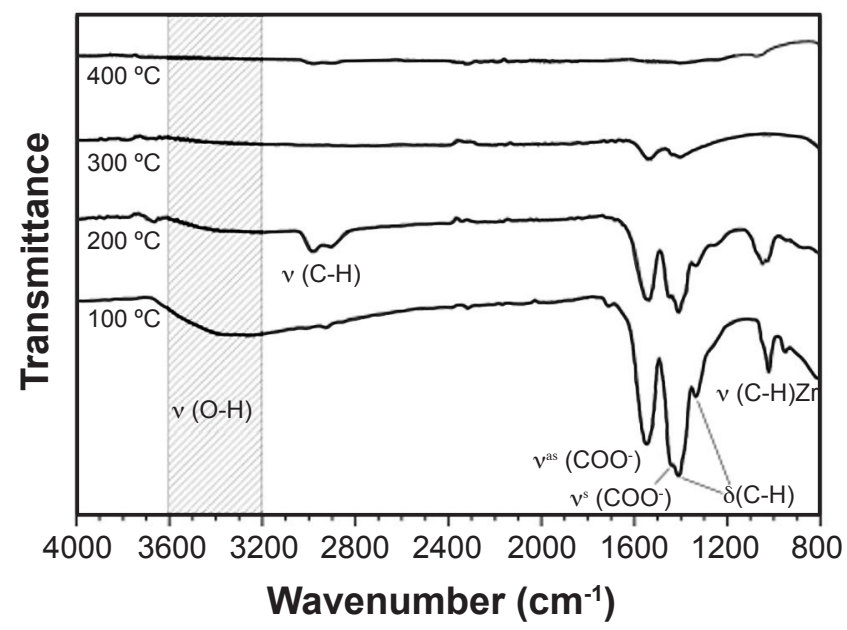

Figure 3: FT-IR spectra of zirconium hydroxide calcined at different temperatures.

band verified on the TG-DTG curves at approximately $330{ }^{\circ} \mathrm{C}$ was due to the thermal decomposition of acetate groups [31]. The next mass loss at around $375{ }^{\circ} \mathrm{C}$ may be assigned to dehydroxylation of $\mathrm{Zr}-\mathrm{OH}$ to form $\mathrm{ZrO}_{2}[26$, 31], since the structure started to undergo a phase transition at approximately $400{ }^{\circ} \mathrm{C}$ (exothermic peak), thus, indicating that this temperature seems to be enough for the calcination of the zirconium hydroxide into tetragonal zirconia.

Chemical modification effect of acetic acid on the molecular structure of zirconium propoxide: infrared spectroscopy is a good technique to obtain information about the coordination mode of acetate ligands. The acetate group in acetic acid has various modes of coordination such as monodentate and bidentate (chelation, bridging or polymeric). Monodentate and bidentate ligands can be unambiguously distinguished based on the frequency separation of the stretching symmetric $v^{s}\left(\mathrm{COO}^{-}\right)$and asymmetric $v^{\text {as }}\left(\mathrm{COO}^{-}\right)[31,33,34]$. According to the FT-IR spectra (Fig. 3), the symmetric and asymmetric vibrations of the acetate group were 1546 and $1447 \mathrm{~cm}^{-1}$, respectively, with a frequency split of $\Delta v=99 \mathrm{~cm}^{-1}$. Such small frequency splitting revealed that the carboxylate group of glacial acetic acid was bonded to the zirconium atoms in a chelating bidentate configuration. Thus, the structural changes shown in Eq. $\mathrm{C}$ are suggested for the chemical modification of acetic acid on the zirconium propoxide molecule [35]. This result is compatible with that found by other authors [20, 30, $31,34]$ and illustrates that the acetic acid suits as a chelating ligand to modify the hydrolysis process of zirconia synthesis from zirconium propoxide.

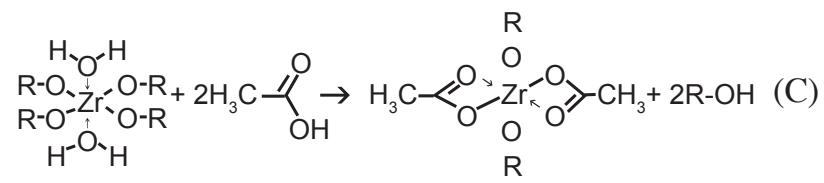

Crystallization behavior: as well known, calcination can result in the growth and transformation of zirconia crystallite $[2,36,37]$. It was investigated the effect of temperature on the crystallographic evolutions for zirconium oxide synthesized with different water contents after drying at $100{ }^{\circ} \mathrm{C}$ for 3 days and calcination at 200,300 and $400{ }^{\circ} \mathrm{C}$. The samples obtained from the three syntheses presented the same structural behavior with the increase of calcination temperature. The characteristic diffraction patterns of the samples for the different temperatures employed are shown in

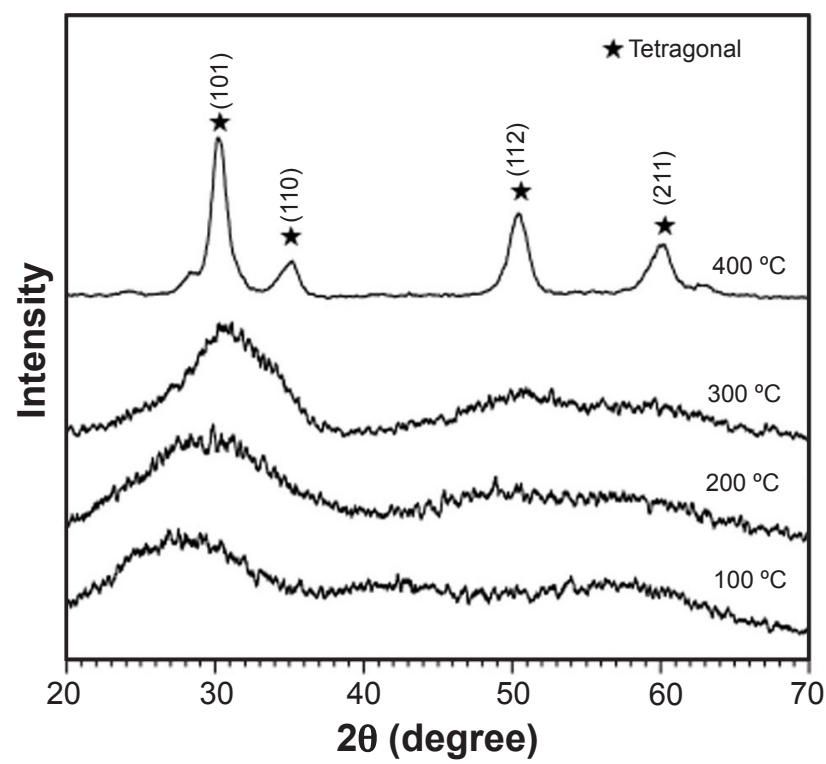

Figure 4: XRD patterns of zirconia heat treated at different temperatures. 
Fig. 4. Samples calcined at temperatures up to $300{ }^{\circ} \mathrm{C}$ had a broad diffraction pattern which is characteristic of amorphous zirconia. At $400{ }^{\circ} \mathrm{C}$, diffraction peaks close to the values of tetragonal $(t)$ phase of zirconia can be seen (JCPDS \#88-1007). According to the Zr-O (zirconium-oxygen) phase diagram [38], at low temperatures, the most stable phase of $\mathrm{ZrO}_{2}$ is a monoclinic form, which occurs naturally as the mineral baddeleyite, and at ambient pressure, a tetragonal structure becomes thermodynamically stable only at $1205^{\circ} \mathrm{C}$ $[37,38]$. Thus, the metastable t-phase zirconia was obtained when calcined at $400{ }^{\circ} \mathrm{C}$. Assessing the results from the DSC curve (Fig. 2), it can be concluded that the exothermic peak really corresponded to the phase transition of amorphous to metastable tetragonal zirconia, and also that this phase transition initiated at approximately $400{ }^{\circ} \mathrm{C}$.

Influence of water content on the surface area and pore structure: the results from nitrogen adsorption-desorption analysis for the samples heat-treated at $400{ }^{\circ} \mathrm{C}$ comprised the nitrogen adsorption-desorption isotherms (Fig. 5) of samples, the pore size distribution (Fig. 6), specific surface areas derived from the BET theory (Table II), and finally, the total pore volumes of samples (Table II). The samples exhibited isotherms type IV(a) [39] which is characteristic of materials containing mesopore size $(2-50 \mathrm{~nm})$, this is in perfect agreement with the pore size distribution (Fig. 6). All the isotherms clearly revealed capillary condensation accompanied by a hysteresis loop classified as H2 [39], which is characteristic of disordered porous materials assembled with complex pore systems such as ink-bottle shape pores and pore networks with cavities connected by constrictions. In such materials, most the cavities are located within the porous material and have no direct access to the gas reservoir but indirect access through many constrictions and cavities [4042]. As shown in Table II, the samples Zr-MC-4 and Zr-MC-6 exhibited higher values of specific surface area and pore volume, while the sample $\mathrm{Zr}$-MC-2 presented poor results for these characteristics. It can be expected that for smaller water molar ratios $(r<4)$ linear polymerization is mainly involved and the network obtained is weakly crosslinked; whereas, for higher water molar ratios $(r \geq 4)$ three-dimensional

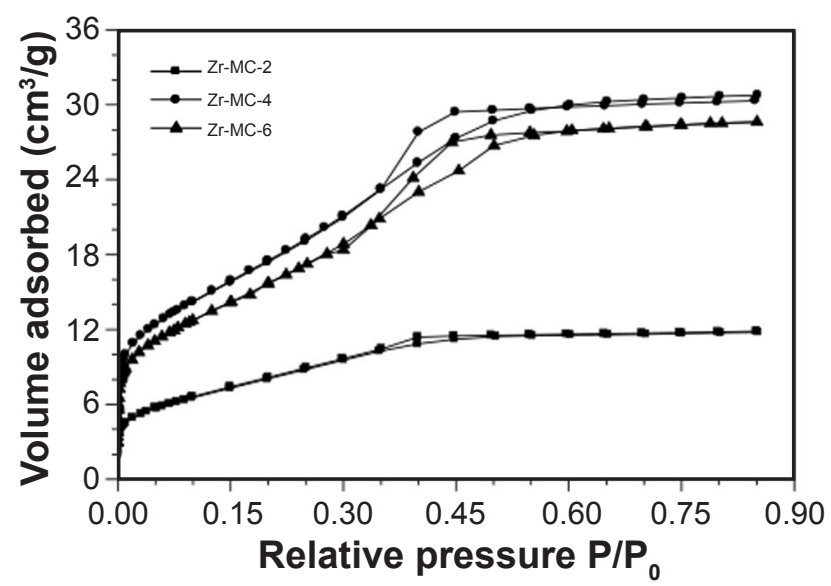

Figure 5: $\mathrm{N}_{2}$ adsorption-desorption isotherms of zirconia with different amounts of hydrolysis water.

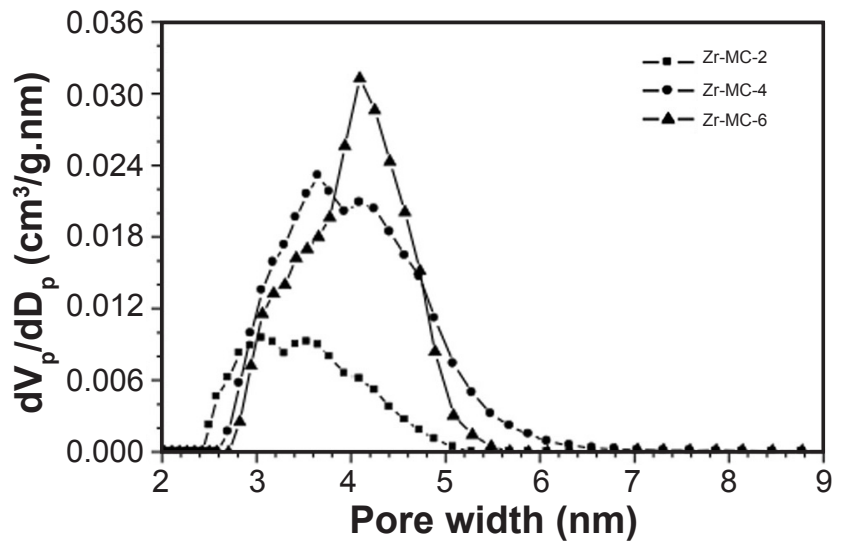

Figure 6: Pore size distribution curves of $\mathrm{ZrO}_{2}$ with different amounts of hydrolysis water.

Table II - Textural characteristics of samples according to nitrogen adsorption-desorption analysis.

\begin{tabular}{ccc}
\hline Sample & $\begin{array}{c}\text { Surface area } \\
\left(\mathrm{m}^{2} / \mathrm{g}\right)\end{array}$ & $\begin{array}{c}\text { Total pore volume } \\
\left(\mathrm{cm}^{3} / \mathrm{g}\right)\end{array}$ \\
\hline Zr-MC-2 & 30.19 & 0.018 \\
Zr-MC-4 & 66.47 & 0.046 \\
Zr-MC-6 & 58.61 & 0.043 \\
\hline
\end{tabular}

polymerization might take place and the resultant network is highly crosslinked. Thus, the sample Zr-MC-2 had an inorganic network weakly crosslinked, wherein the readily reordering of atoms or bonding reactions crossing the linear molecular chains might facilitate the densification process during heat treatment [28]. These results indicated that when using low molar ratios of water $(r<4)$ the sintering process of zirconia structure occurs more easily, and structures with extremely low porosities are obtained.

\section{CONCLUSIONS}

The sol-gel synthesis of zirconia using the metal-chelate route was successfully carried out in this work. The results demonstrated that the molar ratio of hydrolysis water had a great effect on the sol rheology and textural properties of zirconia. The gelation time decreased from $120 \mathrm{~h}$ to only $5 \mathrm{~h}$ when the water content was increased. Furthermore, the enhance in surface area and pore volume was favored when higher amounts of water $(r \geq 4)$ were used in the synthesis. Meanwhile, there was no evidence that the thermal behavior of the samples was affected by the water molar ratios utilized.

\section{ACKNOWLEDGMENTS}

The authors are thankful for the financial support provided by the Brazilian research institutions CAPES and FAPEMIG.

\section{REFERENCES}

[1] S. Nath, A. Biswas, P.P. Kour, L.S. Sarma, U.K. Sur, B.G. Ankamwar, J. Nanosci. Nanotechnol. 18 (2018) 5390. 
[2] Z. Yu, B. Liu, H. Zhou, C. Feng, X. Wang, K. Yuan, X. Gan, L. Zhu, G. Zhang, D. Xu, Appl. Surf. Sci. 399 (2017) 288.

[3] A. Gossard, F. Grasland, X. Le Goff, A. Grandjean, G. Toquer, Solid State Sci. 55 (2016) 21.

[4] V. Thakare, Int. J. Eng. Res. Dev. 5 (2012) 2278.

[5] C. Wang, T. Liu, X. Wang, J. Li, H. Jin, J. Yu, M. Yi, Y. Mo, Sensor. Actuat. B Chem. 270 (2018) 518.

[6] C. Son, A. Bhardwaj, J.W. Hong, J.W. Kim, H.S. Moon, H.S. Noh, S.J. Song, Ceram. Int. 43 (2017) 4083.

[7] W. Zhou, Z. Ma, S. Guo, M. Wang, J. Wang, M. Xia, L. Jia, B. Hou, D. Li, Y. Zhao, Appl. Surf. Sci. 427 (2018) 867.

[8] Y. Kamimura, A. Endo, Phys. Chem. Chem. Phys. 18 (2016) 2699.

[9] K. Pokrovski, K.T. Jung, A.T. Bell, Langmuir 17 (2001) 4297.

[10] H.R. Abid, G.H. Pham, H.M. Ang, M.O. Tade, S. Wang, J. Colloid Interf. Sci. 366 (2012) 120.

[11] H.R. Abid, J. Shang, H. Ang, S. Wang, Int. J. Smart Nano Mater. 4 (2013) 1.

[12] H. Huang, W. Zhang, F. Yang, B. Wang, Q. Yang, Y. Xie, C. Zhong, J.R. Li, Chem. Eng. J. 289 (2016) 247.

[13] A. Majedi, F. Davar, A. Abbasi, J. Environ. Chem. Eng. 6 (2018) 701.

[14] C.J. Brinker, G.W. Scherer, E.P. Roth, J. Non Cryst. Solids 72 (1985) 345.

[15] W. Xia, F. Wang, X. Mu, K. Chen, A. Takahashi, I. Nakamura, T. Fujitani, Catal. Commun. 90 (2017) 10.

[16] F.F. Oloye, R. Aliyev, J.A. Anderson, Fuel 222 (2018) 569.

[17] R.J. Madon, P. Nagel, D.S. Thakur, "Copper-zirconia catalyst and method of use and manufacture", U.S. Patent n. 9,868,113 (2018).

[18] F. Ciesielczyk, J. Goscianska, J. Zdarta, T. Jesionowski, Colloids Surfaces A Physicochem. Eng. Asp. 545 (2018) 39.

[19] A. Sinhamahapatra, J.P. Jeon, J. Kang, B. Han, J.S. Yu, Sci. Rep. 6 (2016) 1.

[20] W. Huang, J. Yang, X. Meng, Y. Cheng, C. Wang, B. Zou, Z. Khan, Z. Wang, X. Cao, Chem. Eng. J. 168 (2011) 1360.

[21] S. Sakka, Handbook of sol-gel science and technology: processing, characterization and applications, Kluwer
Acad. Publ., Osaka (2005).

[22] M. Kakihana, J. Sol-Gel Sci. Technol. 6 (1996) 7.

[23] M. Kakihana, M. Yoshimura, Bull. Chem. Soc. Jpn. 72 (1999) 1427.

[24] P.C. Marr, A.C. Marr, Green Chem. 18 (2015) 105.

[25] D. Levy, M. Zayat, The sol-gel handbook: synthesis, characterization and applications, John Wiley Sons, New Jersey (2015).

[26] J. Zhao, W. Fan, D. Wu, Y. Sun, J. Non Cryst. Solids 261 (2000) 15.

[27] C. Gaglieri, R.T. Alarcon, R.G. Machado, D.S.S. Padovini, F.M.L. Pontes, F.J. Caires, Thermochim. Acta 653 (2017) 59.

[28] C.J. Brinker, G.W. Scherer, Sol-gel science: the physics and chemistry of sol-gel processing, Academic Press, Boston (1990).

[29] L.L. Hench, J.K. West, Chem. Rev. 90 (1990) 33.

[30] G.Y. Guo, Y.L. Chen, W.J. Ying, Mater. Chem. Phys. 84 (2004) 308.

[31] M.T. Colomer, J. Sol-Gel Sci. Technol. 67 (2013) 135.

[32] Z. Zhang, J. Liu, F. Wang, J. Kong, X. Wang, Ceram. Int. 37 (2011) 2549.

[33] S. Doeuff, M. Henry, C. Sanchez, J. Livage, J. Non Cryst. Solids 89 (1987) 206.

[34] H. Hayashi, H. Suzuki, S. Kaneko, J. Sol-Gel Sci. Technol. 12 (1998) 87.

[35] J.C.S. Wu, L.C. Cheng, J. Memb. Sci. 167 (2000) 253.

[36] F. Davar, A. Hassankhani, M.R. Loghman-Estarki, Ceram. Int. 39 (2013) 2933.

[37] L. Zhong, X. Chen, H. Song, K. Guo, Z. Hu, RSC Adv. 4 (2014) 31666.

[38] J.P. Abriata, J. Garces, R. Versaci, Bull. Alloy Phase Diagr. 7 (1986) 116.

[39] M. Thommes, K. Kaneko, A.V. Neimark, J.P. Olivier, F. Rodriguez-Reinoso, J. Rouquerol, K.S.W. Sing, Pure Appl. Chem. 87 (2015) 1051.

[40] A. Grosman, C. Ortega, Langmuir, Am. Chem. Soc. 24 (2008) 3977.

[41] Y. Zeng, L. Prasetyo, S.J. Tan, C. Fan, D.D. Do, D. Nicholson, Chem. Eng. Sci. 158 (2017) 462.

[42] K.A. Cychosz, R. Guillet-Nicolas, J. García-Martínez, M. Thommes, Chem. Soc. Rev. 46 (2017) 389.

(Rec. 31/08/2018, Rev. 15/10/2018, Ac. 24/10/2018) 